Gut, 1963, 4, 373

\title{
The absorption of water, sodium, and potassium in the large intestine with particular reference to the effects of villous papillomas
}

\author{
H. L. DUTHIE AND J. D. ATWELL \\ From the University Department of Surgery, Leeds
}

EDITORIAL SYNOPSIS The absorption of water, sodium, and potassium from isolated segments of the large intestine has been studied in 11 patients. In eight control segments adjacent to a carcinoma of the colon, absorption of water and sodium and secretion of potassium occurred. In five segments of intestine containing a villous papilloma, water, sodium, and potassium were secreted. The difference is mainly due to an increase in exsorption of sodium and water, insorption being relatively unaffected.

Very few observations have been made on the absorption of water and electrolytes from the human large intestine. Two groups of workers have studied the net movements in conscious patients. In two subjects Annis and Alexander (1952) measured the absorption of water, sodium, and chloride from the rectum and colon which had been isolated by a left iliac colostomy as a stage in the treatment of perforation of the colon. In another patient Parsons, Powell, and Pyrah (1952) measured the amount of water, sodium, chloride, and potassium absorbed from urine instilled into an isolated loop of distal large intestine after unilateral uretero-sigmoidostomy. Results were similar in all three patients and showed a more rapid absorption of chloride than sodium and an increase in the content of potassium in the bowel fluid.

The concept of bidirectional transport of water and electrolytes across the intestinal mucosa during absorption was established by Visscher, Varco, Carr, Dean, and Erickson (1944) as a result of radioisotopic studies in isolated loops of canine intestine. Measurements of these individual movements in both directions across the intestinal mucosa would be desirable in man, as determinations of net movement could only give a restricted amount of information and the basic cause of any alteration in absorption might be hidden. In order to study these basic mechanisms, Levitan, Fordtran, Burrows, and Ingelfinger (1962) measured the bidirectional movement of water and the net absorption of sodium from the entire human colon in conscious subjects. They introduced a trans- nasal intestinal tube into the caecum and passed a rectal tube to a height of $8 \mathrm{~cm}$. from the anal margin. The test solution, containing tritiated water, was perfused at a constant rate of $10 \mathrm{ml}$. per minute and the insorption and exsorption rates of water were calculated to be $7 \cdot 8$ and $6.0 \mathrm{ml}$. per minute respectively. Simultaneous determinations of the bidirectional movement of water, sodium, and potassium across isolated loops of human large intestine have not been reported before nor has any measurement been made of the effects of a villous papilloma.

Much information has become available on the changes produced in the electrolyte content of faeces by villous papillomas since the first example of the characteristic depletion syndrome was reported by McKittrick and Wheelock (1954). A profuse, watery diarrhoea leads to excessive losses of water, sodium, potassium, and chloride to produce a clinical picture of prerenal uraemia, hyponatraemia, hypokalaemia, and hypochloraemia with a metabolic acidosis (Shnitka, Friedman, Kidd, and MacKenzie, 1961). In an attempt to discover the mechanism of these lorses, we have measured the bidirectional rates of transport of water, sodium, and potassium in isolated loops of human large intestine and in similar loops containing a villous papilloma.

\section{METHOD}

Isolated loops of intestine were studied at operation on patients undergoing radical surgery for disease of the large intestine. Observations were made on 11 patients. 
In five patients, the isolated loop contained a villous papilloma of rectum or sigmoid. Control observations were made on segments of normal bowel adjacent to the villous papilloma in two of these patients, and in similar normal segments adjacent to a carcinoma in six further patients.

A standard régime was used for anaesthesia. This consisted of thiopentone induction, nitrous oxide and oxygen, and supplements of pethidine for maintenance, with muscle relaxants and controlled respiration. At operation, through a left paramedian incision, the loop of intestine required for the test was mobilized with the minimum of handling. A loop about 13 to $14 \mathrm{~cm}$. long was isolated between stout silk ligatures which were tied to occlude the lumen but not to interfere with the blood supply. The serosal area of the loop was approximately 100 sq. $\mathrm{cm}$. (range $80-115 \mathrm{sq} . \mathrm{cm}$.). A sterile polythene cannula $(4 \mathrm{~mm}$. internal diameter), with multiple side holes in the distal $12 \mathrm{~cm}$., was placed in the intestine through a small opening made on the antimesenteric border and was held in position by invaginating sutures. The loop of intestine was then replaced in the abdomen to prevent cooling which would affect absorption. The tubing was handed to an assistant who performed the test with suitable precautions to prevent contamination of the wound.

The test solution used was modified Tyrode's solution (Code and McIntire, 1956) which was kept at $38^{\circ} \mathrm{C}$. in a water bath. The $p \mathrm{H}$ had been adjusted to 7.0 by the addition of $\mathrm{N} / 10$ hydrochloric acid. The test solution was labelled with radioactive istopes of water, sodium, and potassium $\left({ }^{3} \mathrm{H},{ }^{24} \mathrm{Na},{ }^{42} \mathrm{~K}\right)$. During the test each patient received a maximum of $5 \mu \mathrm{c}$. tritium, $0 \cdot 2 \mu \mathrm{c}$. ${ }^{24} \mathrm{Na}$, and $0 \cdot 2 \mu \mathrm{c} .{ }^{42} \mathrm{~K}$ into the isolated loop.

After isolation and cannulation of the loop of colon, the following procedure was used. The loop was gently rinsed with Tyrode's solution until clean, emptied, and left for 10 minutes. Fifty millilitres of the labelled Tyrode's solution was pipetted into a syringe, injected into the loop and immediately aspirated and reinjected twice to ensure adequate mixing with any fluid remaining from the rinse. A aliquot of $15 \mathrm{ml}$. was removed. The remaining fluid was reintroduced and left in the loop for exactly 10 minutes. Stasis in the loop was prevented by aspiration and reinjection of the contents at three and at seven minutes. At 10 minutes, the loop was emptied as quickly as possible and the volume of fluid measured. The loop was immediately washed with $100 \mathrm{ml}$. of Tyrode's solution and the volume noted. The time taken for the entire procedure varied between 30 and 40 minutes.

After operation, the length of intestine used for the test was opened longitudinally and pinned out on a cork board under uniform tension. The serosal surface area was measured and subsequently the results of the test were expressed in terms of $100 \mathrm{sq} . \mathrm{cm}$. serosal area. The excised specimens were photographed after fixing and were subjected to pathological examination.

The concentration of sodium and potassium in the test solution was determined by means of a flame photometer. The mixture of isotopically labelled sodium and potassium was measured by simultaneous counting in a well type of thallium-activated sodium iodide scintillation counter and in a thick-walled Geiger-Muller counter. Specimens of water for tritium counting were prepared by a modification of the method described by Vaughan and Boling (1961) using continuous vacuum sublimation. Samples of $1 \mathrm{ml}$. of the sublimate were mixed with $10 \mathrm{ml}$. liquid scintillator ${ }^{1}$ and counted in a liquid scintillation spectrometer. All counts were over 10,000 except for the rinse solution when at least 4,000 counts were obtained.

TERMINOLOGY A modification of the terminology introduced by Code (1960) was used to denote the various movements of water, sodium, and potassium. The movement from bowel lumen to the blood stream was called insorption and the movement in the opposite direction exsorption. If the difference between these two movements resulted in a net gain to the body absorption had occurred. If the resultant was a net loss, secretion had occurred.

CALCUlation Corrections were made for the residual volumes of fluid remaining in the lumen of the bowel and polythene tubing at the start and finish of the test. When the test solution was injected at the beginning of the test it was diluted by fluid remaining in the loop and so reduced the counts per millilitre. This reduction was proportional to the volume remaining in the loop and was measured in the aliquot specimen. Therefore, the residual volume could be calculated. It ranged between 0.5 and $7.5 \mathrm{ml}$. Similarly, at the end of the test, the non-radioactive rinse solution washed out any residual radioactivity in the loop and tubing. The acquired radioactivity of a sample of this rinse solution was measured. The total amount of this activity was divided by the counts per millilitre of the solution withdrawn at 10 minutes, so giving the residual volume. The volume of the residual fluid remaining in the locp on completion of the test ranged between 2.7 and $15.0 \mathrm{ml}$. The latter procedure assumed that no absorption of radioactivity took place in the few seconds which elapsed between the end of the test and the first rinse.

The individual counts due to sodium and potassium in the specimens were calculated by the method described by Veall and Vetter (1958) which depends upon simultaneous counting in the well-type scintillation and Geiger-Muller counters. Insorption of water, sodium, and potassium across the intestinal mucosa was calculated by the method of Visscher et al. (1944). Knowing the net transfer, calculated from chemical and volume estimations, and the insorption, determined by isotopic methods, exsorption can be calculated by substitution in the formula: net movement $=$ insorption - exsorption.

The levels of electrolytes and urea in the serum were determined on several occasions pre-operatively in patients with villous papillomas. A measurement of the total body potassium was made in four patients with villous papillomas using a whole body counter (Burch, Hughes, Iinuma, Overton, and Appleby, 1962). These measurements were used to assess the extent of any electrolyte depletion. Specimens of mucus were collected on three occasions from the rectum of one patient with a villous papilloma and the concentration of sodium and potassium was determined.

'Nuclear Enterprises NE 220. 
TABLE I

NET MOVEMENT, INSORPTION AND EXSORPTION OF WATER, SODIUM, AND POTASSIUM IN EIGHT CONTROL LOOPS OF NORMAL LARGE INTESTINE (PER 100 SQ. CM. SEROSAL AREA)

\begin{tabular}{|c|c|c|c|c|c|c|c|c|c|c|}
\hline Patient No. & Site of Loop & $\begin{array}{l}\text { Net Moven } \\
\mathrm{H}_{2} \mathrm{O} \text { (ml.) }\end{array}$ & $\begin{array}{l}\text { nent } \\
N a .(\mu E q .)\end{array}$ & $K(\mu E q)$. & $\begin{array}{l}\text { Insorption } \\
\mathrm{H}_{2} \mathrm{O}(\mathrm{ml} .)\end{array}$ & $N a(\mu E q)$. & $K(\mu E q)$. & $\begin{array}{c}\text { Exsorption } \\
\mathrm{H}_{2} \mathrm{O}(\mathrm{ml} .)\end{array}$ & $N a(\mu E q)$. & $(\mu \Sigma q) K$. \\
\hline 6 & Sigmoid & +0.9 & +289 & & 10.6 & 423 & & $9 \cdot 7$ & 134 & \\
\hline 7 & Sigmoid & +6.0 & +989 & -56 & $43 \cdot 0$ & 1,278 & 65 & $37 \cdot 0$ & 289 & 121 \\
\hline 8 & Sigmoid & $+3 \cdot 3$ & & -33 & $15 \cdot 0$ & & 25 & $11 \cdot 7$ & & 58 \\
\hline 9 & Sigmoid & -1.0 & -152 & & $6 \cdot 2$ & 226 & & $7 \cdot 2$ & 378 & \\
\hline 10 & Sigmoid & $+3 \cdot 2$ & +602 & -41 & $7 \cdot 6$ & 651 & 27 & $4 \cdot 4$ & 49 & 68 \\
\hline 11 & Sigmoid & $+1 \cdot 3$ & & -17 & $3 \cdot 3$ & & 17 & $2 \cdot 0$ & & 34 \\
\hline 1 & Recto-sigmoid & +0.5 & +66 & -24 & $8 \cdot 3$ & & & $7 \cdot 8$ & & \\
\hline 2 & Rectum & -1.0 & & -109 & $13 \cdot 3$ & & 13 & $14 \cdot 3$ & & 122 \\
\hline Mean & & $+1 \cdot 7$ & +359 & -47 & $13 \cdot 4$ & 645 & 30 & $11 \cdot 8$ & 213 & 81 \\
\hline
\end{tabular}

TABLE II

NET MOVEMENT, INSORPTION AND EXSORPTION OF WATER, SODIUM, AND PCTASSIUM IN FIVE LOOPS OF LARGE INTESTINE CONTAINING VILLOUS PAPILLOMAS (PER 100 SQ. CM. SEROSAL AREA)

\begin{tabular}{|c|c|c|c|c|c|c|c|c|c|c|c|}
\hline \multirow[t]{2}{*}{ Patient } & \multirow[t]{2}{*}{ No. } & \multirow[t]{2}{*}{ Site of Papilloma } & \multicolumn{3}{|c|}{ Net Movement } & \multicolumn{3}{|l|}{ Insorption } & \multicolumn{3}{|c|}{ Exsorption } \\
\hline & & & $\mathrm{H}_{2} \mathrm{O}(\mathrm{ml})$. & $N a(\mu E q)$. & $K(\mu E q)$. & $\mathrm{H}_{2} \mathrm{O}(\mathrm{ml})$. & $N a(\mu E q)$. & $K(\mu E q)$. & $\mathrm{H}_{2} \mathrm{O}(\mathrm{ml})$. & $N a(\mu E q)$. & $K(\mu E q)$. \\
\hline \multirow{8}{*}{ Mean } & 1 & Rectum & -0.5 & -1 & -45 & 2.9 & & & 3.4 & & \\
\hline & 2 & Rectum & -3.8 & & -120 & 5.9 & & 7 & 9.7 & & 127 \\
\hline & & & $-2 \cdot 2$ & -1 & -83 & $4 \cdot 4$ & & 7 & 6.6 & & 127 \\
\hline & 3 & Sigmoid & $-5 \cdot 1$ & -695 & -158 & $12 \cdot 8$ & 638 & 37 & 17.9 & 1.333 & 195 \\
\hline & 4 & Sigmoid & -3.6 & -217 & -174 & $24 \cdot 3$ & 1,648 & 61 & $27 \cdot 9$ & 1,865 & 235 \\
\hline & 5 & Sigmoid & -19.1 & -2514 & -178 & & 533 & 10 & & 3,047 & 188 \\
\hline & & & $-9 \cdot 3$ & -1142 & -170 & $18 \cdot 6$ & 940 & 36 & $22 \cdot 9$ & 2,082 & 206 \\
\hline & Mean & & $-6 \cdot 4$ & -857 & -135 & $11 \cdot 5$ & 940 & 29 & $14 \cdot 7$ & 2,082 & 186 \\
\hline
\end{tabular}

RESULTS

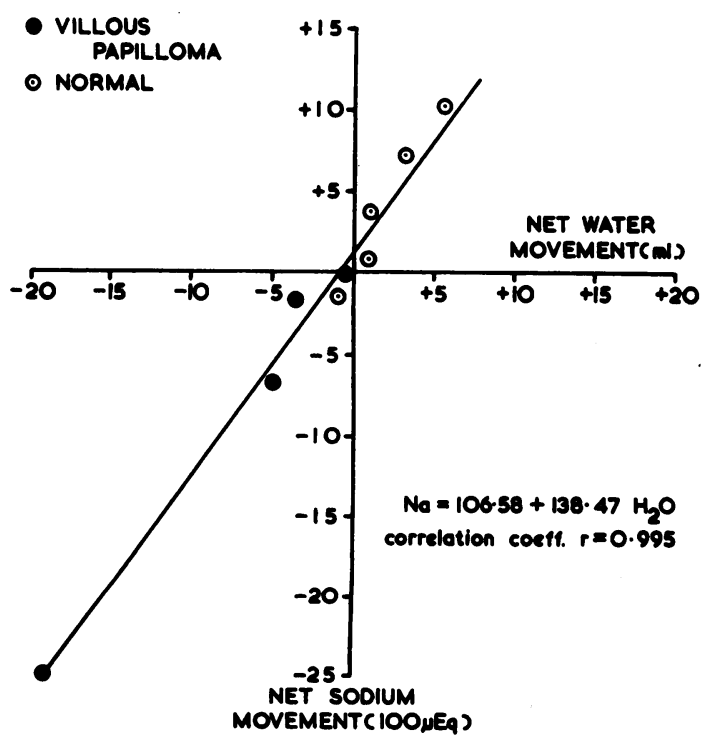

FIG. 1. A linear relationship is shown between the net movement of sodium and the net movement of water from control loops of large intestine and loops containing villous papillomas.
NET MOVEMENT The control loops of sigmoid colon absorbed water and sodium but secreted potassium (Table I). Segments of intestine containing villous papillomas secreted water, sodium, and potassium (Table II). In all loops studied, whether absorbing or secreting, the net movement of sodium bore a direct relationship to the net movement of water (Fig. 1). The fluid lost or gained by the body was approximately isotonic (138 mEq./1). The observations on the villous papillomas were situated in the negative portion of the graph in contrast to the controls. No direct relationship was found between the net movements of potassium and water, the concentration varying between 9 and $90 \mathrm{mEq} . / \mathrm{l}$.

BIDIRECTIONAL RATES OF MOVEMENT Insorption and exsorption of water, sodium, and potassium in the two groups of patients were different (Tables I and II). In loops with villous papillomas exsorption of water, sodium, and potassium was increased, sodium being most affected. Insorption differed only slightly from the control loops.

Histological examination of the specimens of patients 1,2 , and 4 showed carcinoma developing in 
TABLE III

THE PATHOLOGICAL FINDINGS IN THE FIVE VILLOUS PAPILLOMAS

\begin{aligned} Patient No. & Site & Size $(\mathrm{cm} &$. Histology \\ \hline 1 & Lower rectum & $10 \times 7 &$ Villous papilloma with a small central area of carcinoma \\ 2 & Upper rectum & $12.5 \times 11 &$ Villous papilloma with a small ulcerated carcinoma \\ 3 & Sigmoid colon & $3.5 \times 3.5 &$ Villous papilloma \\ 4 & Sigmoid colon & $5 \times 3 &$ Villous papilloma with areas of well differentiated adenocarcinoma \\ 5 & Sigmoid colon & $3.5 \times 3.5 &$ Villous papilloma \end{aligned}

TABLE IV

SERUM ELECTROLYTES, UREA, AND TOTAL BODY POTASSIUM IN FIVE PATIENTS WITH VILLOUS PAPILLOMAS

\begin{tabular}{|c|c|c|c|c|c|c|}
\hline Patient No. & $N a(m E q . / l)$. & $K(m E q . / l)$. & $C l(m E q . / l)$. & $\mathrm{CO}_{2}(m E q . / l)$. & Urea (mg./100 ml.) & Total Body Potassium (g.) \\
\hline 1 & 131 & $4 \cdot 4$ & 99 & 28 & 36 & \\
\hline 2 & 140 & $4 \cdot 5$ & 106 & 26 & 45 & 79 (control 79) \\
\hline 3 & 137 & $4 \cdot 6$ & 106 & 25 & 41 & 135 (control 120) \\
\hline 4 & 140 & $5 \cdot 1$ & 109 & 25 & 29 & 95 (control 81) \\
\hline 5 & 141 & $4 \cdot 5$ & 108 & 25 & 29 & 70 (control 55) \\
\hline
\end{tabular}

part of the villous papilloma (Table III). Only one patient (no. 1) had biochemical evidence of slight depletion of sodium with a level of $131 \mathrm{mEq} . / 1$. in the serum. The mean concentrations of sodium and potassium in the specimens of rectal mucus from patient no. 2 were 122 and $37 \mathrm{mEq}$./l. respectively.

\section{DISCUSSION}

The method used in this study to measure absorption from isolated loops of intestine in man is similar in concept to those used previously in animals (Visscher et al., 1944; Code, Bass, McClary, Newnum, and Orvis, 1960). It permits comparison of rates of movement of water and electrolytes in both directions across the colonic mucosa and avoids errors due to leakage from the loop. Any variation which might be produced by altered motility does not affect the result in such an isolated preparation. The only previously reported findings on rates of movement from the isolated colon in man depend upon the competence of the ileocaecal valve through which a tube was passed. The entire colon was perfused in the conscious patient (Levitan et al., 1962). Our method does not permit the patient to be conscious and, in this respect, is unphysiological. However, the effect of anaesthesia on movement of water and electrolytes is slight in the dog (Code et al., 1960). The rates obtained in our study are in the same range as those in dogs both as regards colon, reported here, and ileum (Atwell and Duthie, 1963). Furthermore, the rates in control loops of colon were used for direct comparison with the diseased loops which were treated under identical conditions.

It is clear from these results that a loss of water and sodium is an integral part of the changes produced by villous papillomas and that loss of potassium is not all-important. Despite clear clinical data to this end,
(Fitzgerald, 1955; Jordon and Erickson, 1958; Kelley, 1959; Mayfield and Milnor, 1959; Walters, Monks, and Chitty, 1959; Shnitka et al., 1961; Findlay and O'Conner, 1961; Davis, Seavey, and Sessions, 1962; Rabinowitz, Farber, and Friedman, 1962) the idea persists that villous papillomas are mainly potassium-losing. In addition, it can be seen that the losses of electrolytes into the colon can occur without changes in the serum level or signs of depletion, even though the fluid lost is similar in concentration to that in patients with marked depletion. This concentration has been found to be remarkably stable in the case of sodium, about 140 mEq./l. (Fig. 1) whereas potassium showed no such relationship, ranging from 9 to $90 \mathrm{mEq}$./ 1 . This increased concentration of potassium in the colonic fluid, compared with plasma, has been another reason for the emphasis placed upon the loss of potassium.

Many explanations have been advanced for the profuse watery diarrhoea which is symptomatic of villous papilloma of the distal colon and rectum. Previous observations have only been made on net movement. Our findings provide more detail of the possible mechanisms, as insorption and exsorption have been measured. The reversal of the net movement of water and sodium refutes the theory that the diarrhoea might be due to an increased epithelial surface area. In such a case, the relative amounts insorbed and exsorbed would have remained the same, although the absolute amounts would have been greater in the loop containing the villous papilloma. Admittedly, the changes in the rates of insorption and exsorption of potassium could be explained by an increase of epithelial surface area for which no allowance was made in our method of measuring the area of the isolated loop.

Transudation of water and electrolytes was once 
suggested as a cause of the diarrhoea in patients with villous papillomas. Our results confirm previous evidence discounting this mechanism (Cooling and Marrack, 1957). Selective reabsorption of electrolytes in the bowel distal to the tumour has been put forward as the cause of the selective loss of potassium, but potassium loss is only one factor in this depletion. Also, the depletion syndrome occurs in nearly equal numbers in rectal and recto-sigmoid tumours. We have brought forward no direct evidence of reabsorption in the bowel distal to the three growths in the pelvic colon. Even allowing that the distal colon would function as in our control loops, an increased loss of water and potassium would still occur and only sodium losses would be slightly reduced.

We have demonstrated that the losses of water and electrolytes in a loop of bowel containing a villous papilloma are due to an increase in exsorption. It is suggested that this change is due to an intrinsic difference in the cells of the villous papilloma compared with the normal colonic mucosal cells.

We thank Professor J. C. Goligher for his keen interest and encouragement throughout this study, and Dr. C. J. Hayter of the Department of Nuclear Medicine and Mr. G. W. Reed and Mr. A. Smith of the Department of Medical Physics at the General Infirmary, Leeds, for considerable assistance with the radioisotopic techniques.

\section{REFERENCES}

Annis, D., and Alexander, M. K. (1952). Differential absorption of electrolytes from the large bowel in relation to ureterosigmoid anastomosis. Lancet, 2, 603-606.

Atwell, J. D., and Duthie, H. L. (1963). Unpublished observations.

Burch, P. R. J., Hughes, D., Iinuma, T. A., Overton, T. R., and Appleby, D. B. (1962). In Whole Body Counting, pp. 59-77. International Atomic Energy Agency. Vienna,
Code, C. F. (1960). The semantics of the process of absorption. Perspect. Biol. Med., 3, 560-562.

edited by David Glick, vol. 3, p. 66. Interscience, New York.

—, Bass, P., McClary, G. B. Jr., Newnum, R. L., and Orvis, A. L. (1960). Absorption of water, sodium and potassium in small intestine of dogs. Amer. J. Physiol., 199, 281-288.

Cooling, C., and Marrack, D. (1957). Potassium-secreting tumour of the colon. Proc. roy. Soc. Med., 50, 272-274.

Davis, J. E., Seavey, P. W., and Sessions, J. T. Jr. (1962). Villous adenomas of the rectum and sigmoid colon with severe fluid and electrolyte depletion. Ann. Surg., 155, 806-816.

Findlay, C. W. Jr., and O'Connor, T. F. (1961). Villous adenomas of the large intestine with fluid and electrolyte depletion. J. Amer. med. Ass., 176, 404-408.

Fitzgerald, M. G. (1955). Extreme fluid and electrolyte loss due to villous papilloma of the rectum. Brit. med. J., 1, 831-832.

Jordon, G. L. Jr., and Erickson, E. (1958). Villous papilloma of the rectum with severe fluid and electrolyte depletion. Arch. Surg., 77, 248-252.

Kelley, H. G. Jr. (1959). The management of villous adenoma complicated by electrolyte depletion. Amer. J. Surg., 98, 772-774.

Levitan, R., Fordtran, J. S., Burrows, B. A., and Ingelfinger, F. J. (1962). Water and salt absorption in the human colon. J. clin. Invest., 41, 1754-1759.

McKittrick, L. S., and Wheelock, F. C. (1954). Carcinoma of the Colon, pp. 61-63. Thomas, Springfield, Illinois.

Mayfield, L. H., and Milnor, J. P. Jr. (1959). Villous tumor of rectum and a portion of the sigmoid flexure causing severe electrolyte imbalance. Dis. Colon Rect., 2, 311-313.

Parsons, F. M., Powell, F. J. N., and Pyrah, L. N. (1952). Chemical imbalance following ureterocolic anastomosis. Lancet, 2, 599. 602.

Rabinowitz, P., Farber, M., and Friedman, I. S. (1962). A depletion syndrome in villous adenoma of the rectum. Arch. intern. Med., 109, 265-269.

Shnitka, T. K., Friedman, M. H. W., Kidd, E. G., and MacKenzie, W. C. (1961). Villous tumors of the rectum and colon characterized by severe fluid and electrolyte loss. Surg. Gynec. Obstet., 112, 609-621.

Vaughan, B. E., and Boling, E. A. (1961). Rapid assay procedures for tritium-labeled water in body fluids. J. Lab. clin. Med., 57, 159-164.

Veall, N., and Vetter, H. (1958). Radioisotope Techniques in Clinical Research and Diagnosis, chap. 6, pp. 103-121. Butterworths, London.

Visscher, M. B., Varco, R. H., Carr, C. W., Dean, R. B., and Erickson, D. (1944). Sodium ion movement between the intestinal lumen and the blood. Amer. J. Physiol., 141, 488-505.

Walt ers, G., Monks, P. J. W., and Chitty, K. (1959). Metabolic disturbance due to villous papilloma of the rectum. Brit. J. Surg., 47, $177-178$. 